\title{
Pediatric liver transplantation
}

\author{
V. Ibáñez Pradas ${ }^{1}$, M. Cortés Cerisuelo², E. Montalvá Orón ${ }^{1}$ \\ 'Liver Transplantation Unit. La Fe Polytechnic and University Hospital. Valencia (Spain). \\ ${ }^{2}$ Liver and Intestinal Transplant Surgical Service Unit. King's College Hospital. London (UK).
}

\section{INTRODUCTION}

Contrarily to other areas of solid organ transplantation where pediatric patients have benefited from the advances made in the adult population, the history of liver transplantation (LT) is closely related to the pediatric population. On the one hand, the first attempt by Thomas Starzl ${ }^{(1)}$ took place in a child - a 3-year-old patient with biliary atresia. And on the other hand, options such as living donor or "split liver", which have allowed the organ pool to increase globally, are a result of the reduced liver graft introduced by Bismuth ${ }^{(2)}$ in the 1980s, precisely as a result of how difficult it was to obtain adequate organs for pediatric patients.

Since then, technical and perioperative skills have greatly improved. The advances made in the field of immunosuppression have confirmed transplantation as the standard treatment for patients with terminal liver disease and a $<1$-year life expectancy, acute hepatic failure, non-resectable hepatic tumors, and metabolic liver disease, thus improving short- and long-term survival (3).

In Spain, 60 patients are transplanted in five primary institutions (Table I) annually. However, when considering the rest of transplantation units, this number is slightly higher, since adolescents ( $<18$ years of age), if only occasionally, are also transplanted there. LT has a bimodal distribution in children. In infants and children under 2 years of age, it is primarily indicated for biliary atresia and rapidly progressive metabolic diseases, such as neonatal hemochromatosis or tyrosinemia. In older children,

DOI: $10.54847 / \mathrm{cp} .2022 .01 .11$

Corresponding author: Dr. Vicente Ibáñez Pradas.

E-mail address: ibanyez_vic@gva.is

Date of submission: November 2021 Date of acceptance: November 2021 metabolic diseases, fulminant hepatic failure, and cirrhosis are the main indications of LT (Fig. 1) $)^{(4)}$.

Overall, LT results in children are superior to results in adults, with 5-year graft and patient survival rates (S5) of $85 \%$ and $95 \%$, respectively ${ }^{(5.6)}$. These results vary according to age group (higher risk in patients under 2 years of age), historical era, and diagnosis. In the results from the 1991-2019 period, three prognostic groups can be identified - patients with cholestatic and metabolic diseases, with a $>90 \%$ patient S5; patients with acute failure and cirrhosis, with an S5 around 70\%; and patients with hepatocellular carcinoma (14 cases), with a $54 \% \mathrm{~S} 5^{(7)}$.

Even though pediatric LT is well established, it has its own logistic and clinical particularities, which are different from those of LT in adults. Indeed, this procedure proves especially important for these young patients given their vulnerability and how many years their lives could be extended for ${ }^{(8)}$. In this review, we aim to address some of these particularities, while paying special attention to the data generated in our environment and available in the Spanish National Transplantation Organization (NTO) ${ }^{(9)}$ and the Spanish Registry of Liver Transplantation ${ }^{(10)}$ reports.

Table I. Activity in Spain by healthcare institution.

\begin{tabular}{lcccccc} 
& 2015 & 2016 & 2017 & 2018 & 2019 & 2020 \\
\hline Reina Sofía & 8 & 10 & 7 & 8 & 9 & 6 \\
\hline Vall d'Hebrón & 13 & 16 & 10 & 15 & 19 & 18 \\
\hline La Fe & 7 & 5 & 6 & 6 & 10 & 11 \\
\hline La Paz & 32 & 22 & 19 & 32 & 32 & 36 \\
\hline 12 de Octubre & 4 & 2 & 1 & 2 & 3 & 0 \\
\hline Total & $\mathbf{6 4}$ & $\mathbf{5 5}$ & $\mathbf{4 3}$ & $\mathbf{6 3}$ & $\mathbf{7 3}$ & $\mathbf{7 1}$ \\
$\begin{array}{l}\text { Source: Spanish NTO. } \\
\text { S }\end{array}$ & & & & &
\end{tabular}




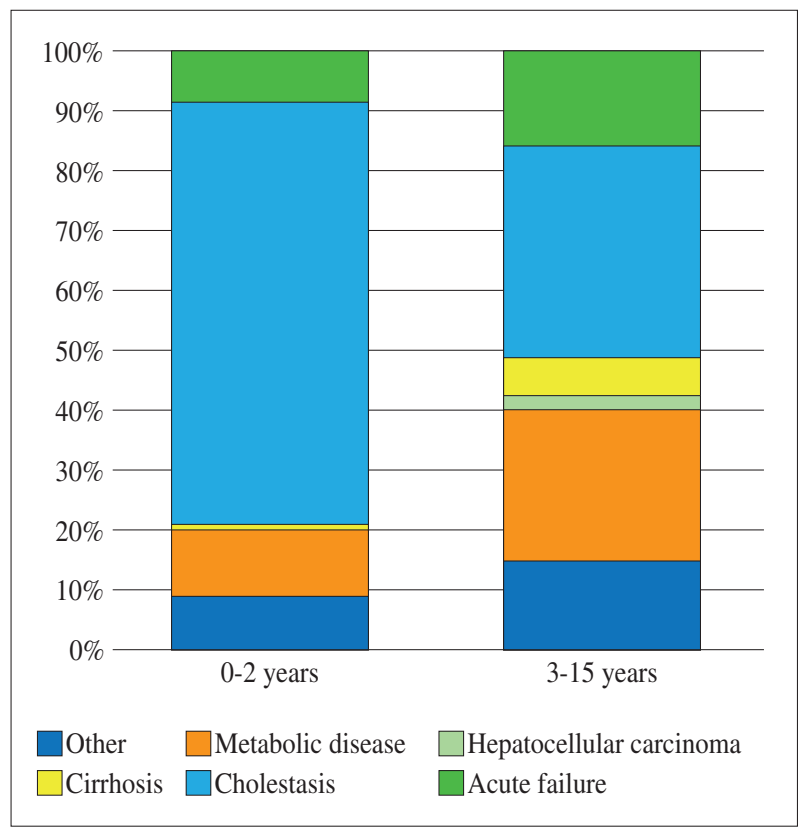

Figure 1. Percentage distribution of pediatric LT indications in Spain (1984-2019). Hepatoblastoma is not included as a separate category.

\section{RELATIVE DONOR SCARCITY}

In pediatric transplantation, donor requirements are greater than in adult transplantation. Mean donor age in Spain is now 59 years old, and although the liver maintains its regeneration capacities permanently, they significantly decline from the age of 40 . In practical terms, older donors offer worse results (Fig. 2), which means they are not eligible for pediatric patients if so permitted by the circumstances of the latter.

Pediatric donors (up to 18 years of age) only represent $2.2 \%$ of the total. When extending age up to 29 years, 90 donors were generated in 2020 for a total of 114 patients on the waiting list. Pediatric donation is especially complex. First, due to low child mortality rates in Spain; and second, because donation rates in children are lower than in adults. Indeed, regarding brain dead patients (BD), 56\% of adults become donors $v s .42 \%$ of pediatric deaths ${ }^{(11)}$. This limitation also applies to a new donation modality - donation after circulatory death (DCD) (Table II)(12). From 2010 to 2019, 294 effective pediatric donors were found, but only $3.7 \%$ were DCD donors. DCD, which already accounts for $26.9 \%$ of the total donations in Spain, has had a direct impact on adult patients, with a reduction in waiting list times. This has not occurred in the pediatric population (Fig. 3).

It is estimated that pediatric DCD (pDCD) could increase overall donation rates in Spain by 20-58\%(13), but implementation is still limited, possibly as a result both of the ethical issues it arises and the need for a specific protocol.

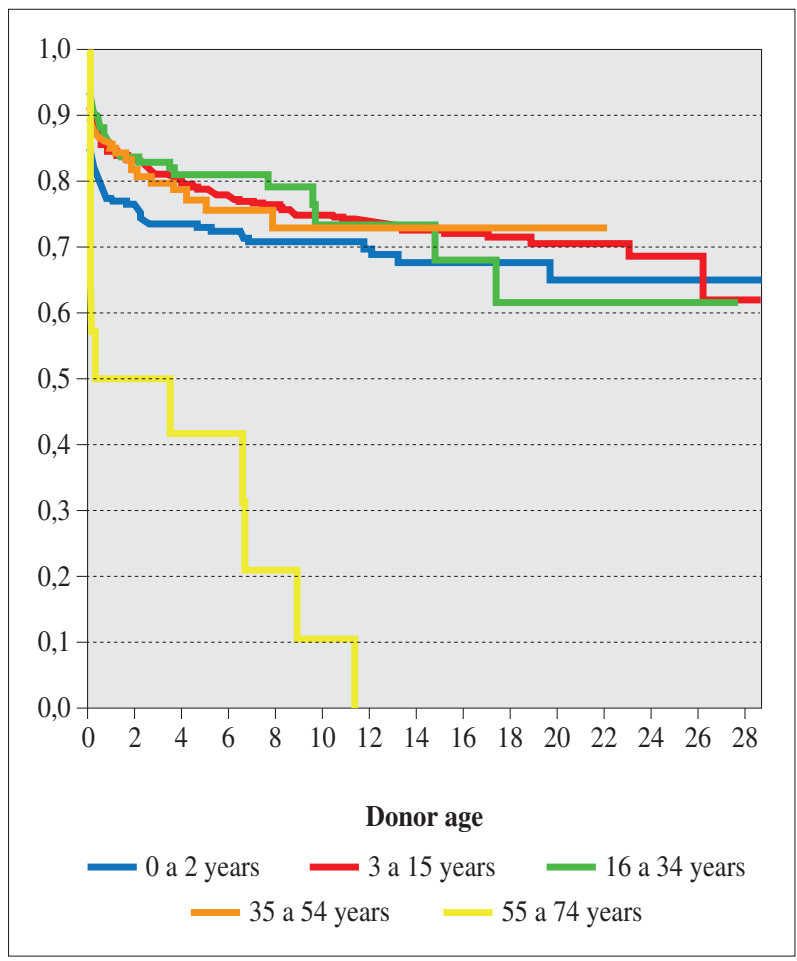

Figure 2. Graft survival according to donor age (1991-2019). Source: Spanish NTO.

Another issue related to DCD has to do with procurement types, with two modalities available. The first one requires the premortem cannulation of the donor to initiate abdominal organ reperfusion through ECMO (postmortem normothermic regional perfusion, PNRP) after 5 minutes of circulatory death - cardiac arrest observation time required to determine death, according to Spanish 1723/2012 Royal Decree ${ }^{(14)}$. The second one is known as the "super quick" modality, where perfusion is to be initiated with preservation solutions less than 5 minutes following death in order to minimize ischemic cholangiopathy risks. The results of donation under PNRP are better than those of super quick procurement, with much lower primary graft failure and ischemic cholangiopathy rates. Therefore, following a national consensus meeting held in 2018, PNRP was adopted as the method of choice for organ procurement in $\mathrm{DCD}^{(15)}$. However, this recommendation does not apply to pediatric donors weighting less than $30 \mathrm{~kg}$ - this is not an absolute limitation, though. In these cases, cervical cannulation (carotid artery and right jugular vein) is the preferred ECMO cannulation method as femoral vessels are smaller. This makes brain flow interruption more complex, since brain flow has to be excluded from postmortem reperfusion. In femoral access, the procedure only requires a Fogarty balloon to be introduced through the contralateral femoral artery on to the thoracic aorta. However, in cervical access, brain occlusion requires ligating the proximal 
Table II. Modified Maastricht classification for donors after circulatory death.

\begin{tabular}{llc} 
Category 1. Uncontrolled & Non-witnessed cardiac arrest without any attempt of resuscitation & $\begin{array}{l}\text { 1a: out of hospital } \\
1 \mathrm{~b}: \text { in hospital }\end{array}$ \\
\hline Category 2. Uncontrolled & Witnessed cardiac arrest with unsuccessful resuscitation & $\begin{array}{l}2 \mathrm{a}: \text { out of hospital } \\
\text { 2b: in hospital }\end{array}$ \\
\hline Category 3. Controlled & Expected cardiac arrest following planned withdrawal of life-sustaining therapy &
\end{tabular}

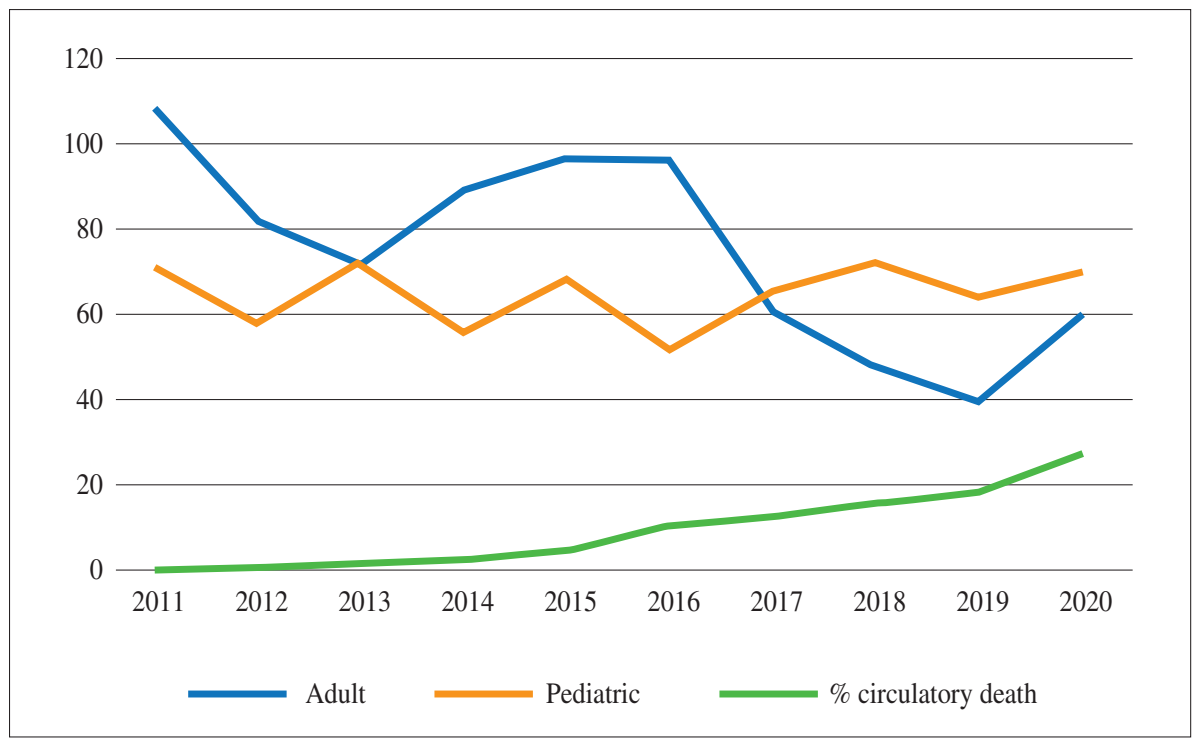

Figure 3. Median waiting list days $v s$. percentage of circulatory death donors. Source: Spanish NTO.

right subclavian artery to the extremity of the vertebral artery, and also the left carotid artery and the left subclavian artery. Therefore, procurement type is to be decided by the surgical team. Super quick procurement requires a well-trained surgical team capable of initiating abdominal organ reperfusion as soon as possible.

Today, the likelihood of receiving an organ in the first year for a child on the waiting list is around 60\%, similar to the adult population (Fig. 4), but median waiting list times (>60 days) are longer (Fig. 3). This is not consistent with the fact pediatric population only represents $5 \%$ of the total patients on the list - 83-114 patients/year in the 2015-2020 period. In this period, mortality while waiting for organ transplantation ranged from $1.8 \%$ to $6 \%$. Even though the Spanish NTO data are not broken down by pediatric age, mortality in patients under 1 year old should be around $10 \%(16)$ - as it is the case in other countries -, given how difficult it is to find an adequately sized organ, and also the complexity of perioperative management.

\section{GREATER USE OF PARTIAL GRAFTS}

Pediatric patients are the main recipients of partial grafts, which increases both donation and transplantation complexity (Fig. 5). In Spain, partial grafts represent two thirds of the total grafts in patients between $0-2$ years of age. The most common ones are living donor graft $(29.3 \%)$, reduced graft $(23.2 \%)$, and split graft $(12.8 \%)$. In the group of patients aged 3-15 years old, the proportion is reversed, with partial grafts representing one third of the total (18.2\% reduced graft, $8.2 \%$ living donor graft, and $6.2 \%$ split graft).

The so-called "split liver" graft generates two transplantable grafts from an optimal donor. The left lateral segment (LLS, lobes II and III) is often used for pediatric patients, and the extended right lobe (segments IV-VIII +/- I) for adult recipients. Until 2019(17), when the Spanish NTO, on a consensual basis, officially allocated grafts from donors aged $\leq 35$ years old to the pediatric waiting list, decisions regarding partial organ donations were made by procurement teams. This gave rise to certain reluctance, since a high-quality organ was replaced by two organs that could be suboptimal should complications arise during partition. A less complex option is liver reduction, where the vascular pedicle is fully allocated to the graft to be implanted, and the remaining parenchyma is cast away.

Survival according to graft type is an example of how technically demanding split graft transplantation $v s$. reduced graft transplantation is. S5 was $80 \%$ for reduced 


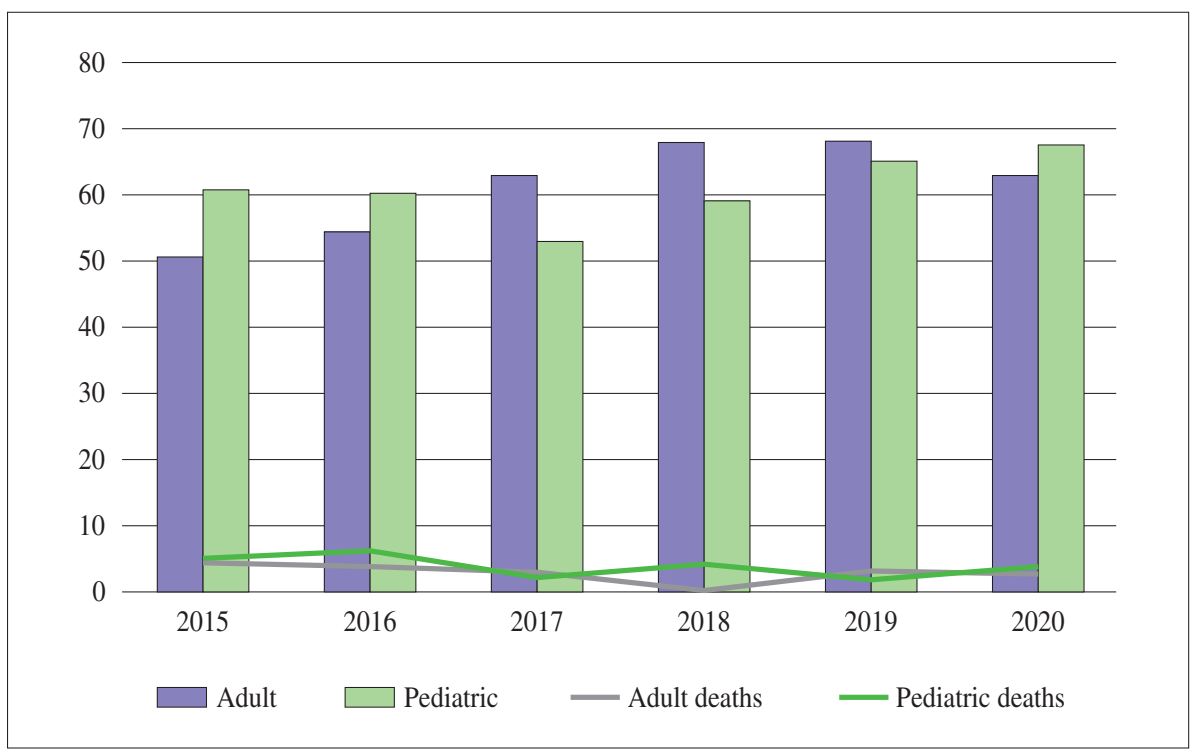

Figure 4. Transplantation and death likelihood while on the waiting list. Source: Spanish NTO.

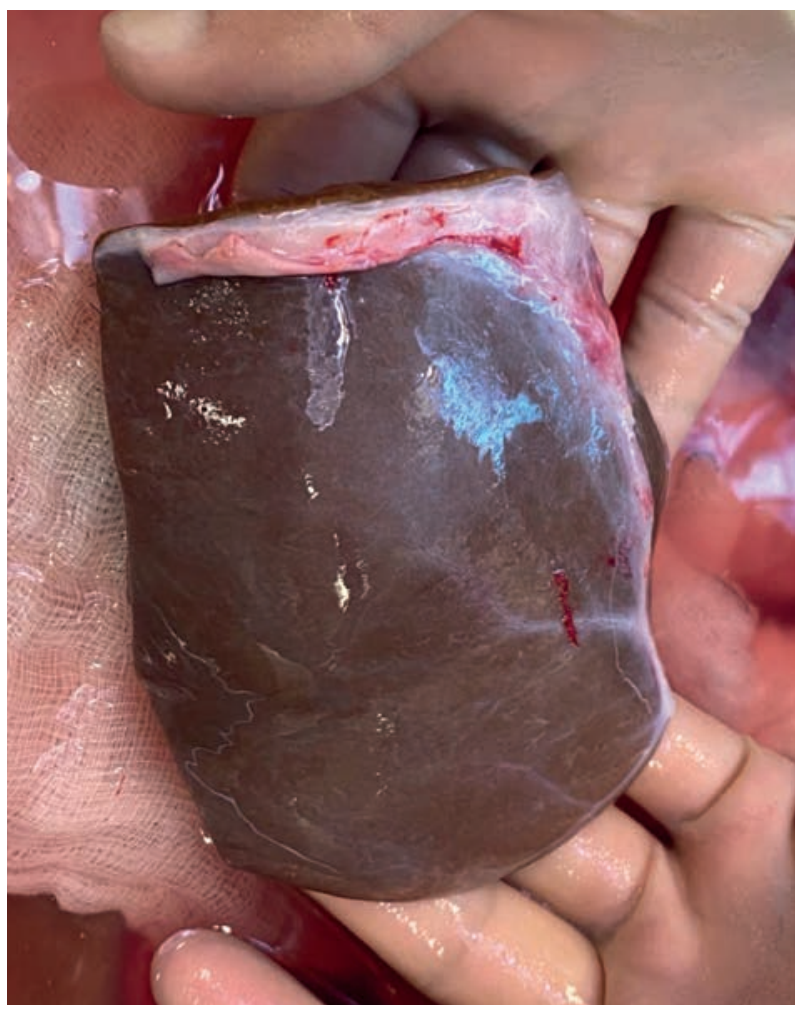

Figure 5. Liver single segment (picture from King's College Hospital).

graft, and 71\% for split graft (1984-2019 period). In addition, the logistic complications associated with extending procurement surgery for an extra 2-3 hours to conduct liver partition in the same procedure ("in-situ split", similar to living donor cases) should also be considered. Once procurement has been completed, the "ex-situ" split demonstrates identical results in terms of survival and morbid-
Table III. Criteria for considering the donor eligible for "split liver.' Spanish NTO's split liver promotion scheme.

Primary endpoints

1 Age $\leq 50$ years

2 Weight $\geq 60 \mathrm{~kg}$

3 Maximum transaminase count $\mathrm{x} 3$ maximum lab count

4 No evidence of steatosis at ultrasonography

Optional endpoints

1 BMI $<28$

2 ICU stay $<7$ days

3 Natremia $\leq 160 \mathrm{mmol} / \mathrm{l}$

4 Maximum 1 vasoactive drug required

5 Distance from donor hospital to recipient hospital $<2$ hours

If primary endpoints are met, optional endpoints are not an absolute contraindication. Final decision will be made by procurement teams.

ity ${ }^{(18)}$, but it inevitably extends cold ischemic times, which means it is not feasible if donor and recipient hospitals are too far away ${ }^{(19)}$. Today, decision as to whether the liver should be divided or not is made by the pediatric team in the case of donors $\leq 35$ years old, and by the adult team if the donor is older. Table III features the criteria to be met by the donor to be considered as "potentially divisible."

Living donor LT generates organs of outstanding quality thanks to the donor's young age - usually the recipient's parents - and short ischemic times. The graft volume - usually the LLS - required for a child implies a minimum risk of complications for the donor, contrarily to living donor LT in adults ${ }^{(20)}$. However, at least $10 \%$ of candidates are 


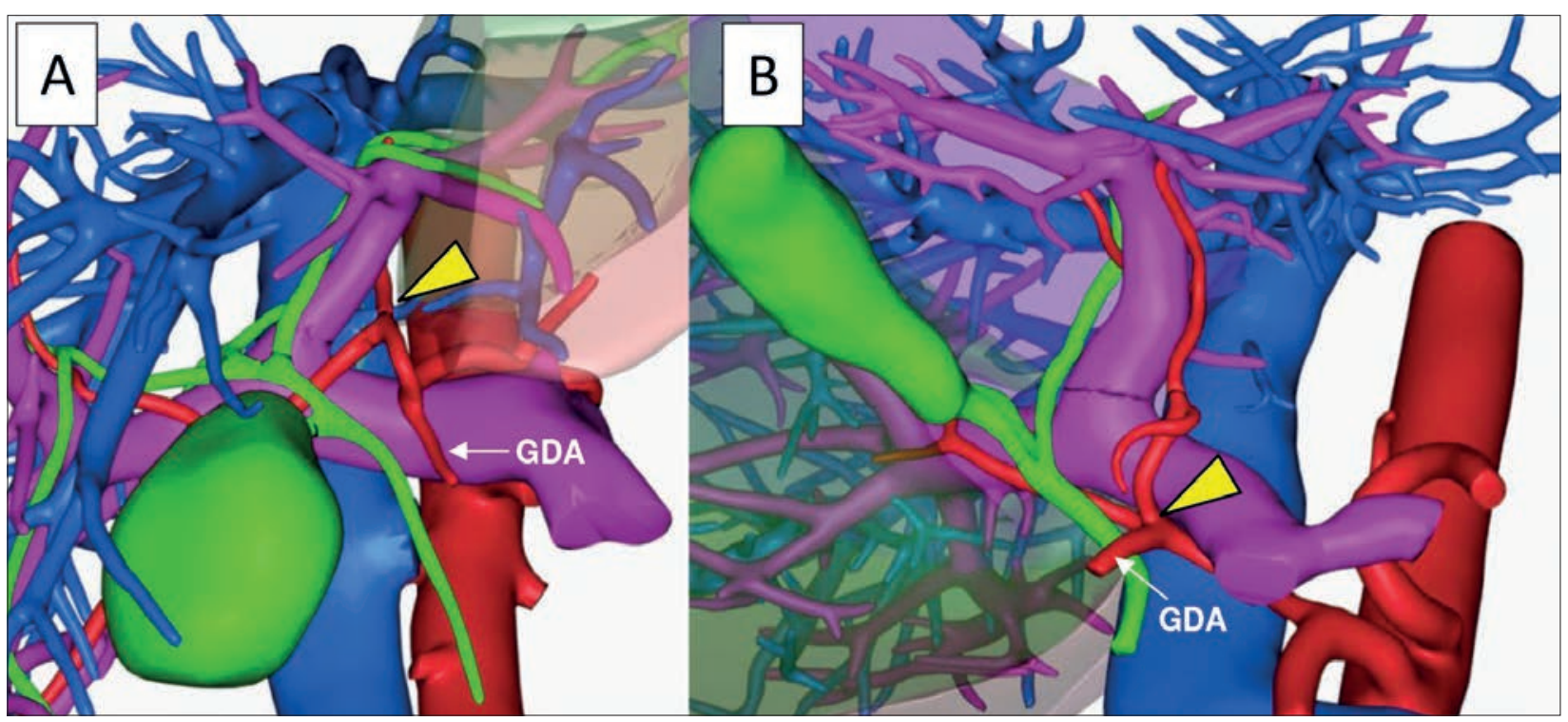

Figure 6. 3D reconstructions of candidates for living related donors (left lateral segment). Donor A was ruled out as the artery was not sufficiently long. GDA: gastroduodenal artery; Arrow: potential left hepatic artery division area.

rejected. The presence of vascular or biliary anatomical variations making the candidate ineligible only accounts for $1-4 \%$ of rejections (Fig. 6). ABO incompatibility and positive viral serology, as well as other donor comorbidities involving an added risk, are far more frequent ${ }^{(21)}$. Donor safety is of the utmost importance, since we are dealing with a healthy person.

\section{SIZE AS AN ISSUE}

Donor-recipient size mismatch, which is frequent, can cause morbidity as a result of transplanted tissue volume discrepancies, which means adequate selection is crucial.

If the graft is too small, it will cause the so-called "small-for-size syndrome" (SFSS) as a result of transplanting an insufficient functional mass, with the resulting high relative portal flow. But SFSS can also occur due to great vessel caliber discrepancies, which may give rise to turbulent flow, or to excessive portal flow as compared to the transplanted liver mass. SFSS manifests as cholestasis, progressive cholangiopathy, portal hypertension, ascites, and gastrointestinal bleeding in more severe cases ${ }^{(22)}$.

The opposite effect is the so-called "large-for-size syndrome" (LFSS), which occurs as a result of poor reperfusion due to low relative portal flow, and also due to mechanical compression following closure of the abdominal cavity, which aggravates microcirculation disorders. LFSS causes long warm ischemia and worsening of the ischemic-reperfusion lesions, which may lead to dysfunction, primary graft failure, and massive hepatic necrosis ${ }^{(23)}$. Issues due to lack of space, vessel kinking or angulation
- especially at the portal and suprahepatic levels -, and inferior vena cava compression should also be considered.

Donor weight is a poor indicator of graft adaption within the recipient. If a full organ is available, it should range from $50 \%$ to $125 \%$ of the recipient's weight. In case of partial graft, the proportions vary $-2: 1$ for the right lobe, 2.5:1-5:1 for the left lobe, and up to 10:1 for the $\operatorname{LLS}^{(24)}$. More accurate formulas are available, but the graft-to-recipient weight ratio (GRWR) is one of the most widely used, especially in the case of partial grafts. A $0.8-1 \%$ GRWR is the standard ratio for partial grafts, but it could be lower, between $0.6 \%$ and $0.8 \%$, in the case of living donor grafts as the quality of these is higher ${ }^{(19)}$. Ratios under $0.7 \%$ are associated with a high risk of SFSS, and $>4 \%$ ratios increase the risk of LFSS. In the pediatric population, GRWR should be around 2\%, since estimated liver mass $v s$. patient weight ratio is higher in children than in adults(25).

Calculations should consider all other factors potentially compromising graft functionality. These include loss of function following ischemia-reperfusion, rejection in the immediate postoperative period, technical issues such as compromised venous outflow, and indication for transplantation, since recipients with advanced liver disease especially severe portal hypertension - require larger and better grafts to reduce the risk of SFSS.

\section{GREATER RISK OF THROMBOSIS}

The large proportion of underweight recipients ${ }^{26)}$ (especially in patients under 2 years of age) and partial grafts, or 
complications such as LFSS - which rarely occurs in adults - result in a three-fold risk of arterial thrombosis (AT) as compared to adults. AT is the most deadly complication of LT, since it compromises immediate and deferred graft viability - due to parenchymal necrosis in the first case, and to ischemic cholangiopathy in the second, given that the biliary tree entirely relies on arterial vascularization. Risk is maximum in the first two weeks, with an estimated incidence of $6 \%$ - this number varies widely according to institutions and eras ${ }^{27)}$. Post-transplantation thrombotic events, regardless of the vessel involved (arterial, portal or hepatic vein thrombosis), range from $2.4 \%$ to $17.3 \%{ }^{(28)}$. In Spain, NTO data on urgent re-transplantation rates are broken down by healthcare institution, which represents an approximate indicator of AT. In addition to increased risk, the difficulty of rescue options - re-transplantation relies on finding an adequate organ - is also to be considered. And endovascular treatment - which is theoretically feasible ${ }^{(29)}$ - is primarily applied in venous thrombosis. An adequate technique, early diagnosis, and urgent surgical repermeabilization are key to address this complication.

In spite of the initial belief that partial grafts were associated with a higher risk of AT, recent studies have demonstrated that risk is lower than that of total grafts. This had already been noted in previous studies ${ }^{(30)}$, but it had been blamed on the "learning curve" effect. This protective effect could be explained by the fact resistance from the distal vascular bed is lower as a result of vessels being thicker, and also by the lower risk of resistance in liver graft due to the transection surface, where there is no capsule. These grafts have been suggested as the grafts of choice in patients under 2 years old - those on the waiting list with higher mortality risks ${ }^{(31)}$.

Technical skills in arterial anastomosis are necessary but not sufficient to minimize the risk of AT. Recommendations by healthcare institutions with high transplantation volumes and low thrombosis incidence mention other aspects to be considered ${ }^{(32)}$ : adequate arterial flow, with anastomosis to the aorta in case of doubtful flow or too narrow calibers; appropriate venous drainage, with triangular anastomosis at the level of the suprahepatic-cava veins being recommended, especially in the case of living donors; deferred wall closure if in doubt in terms of space; and arterial flow monitoring with intraoperative Doppler ultrasound control both at the anastomotic and the intraparenchymal levels. In the postoperative period, aggressive Doppler ultrasound monitoring with daily controls, and even twice a day in the first week, has demonstrated to be more effective than waiting until altered transaminase count results are available to request the test ${ }^{(33)}$.

Finally, all teams apply their own postoperative anticoagulation protocols, which greatly vary globally ${ }^{(28)}$. Most studies show a similar pattern, which initiates when INR levels go below 1.5-2. Standard treatment includes heparin (continuous perfusion with sodium heparin, or low molecular weight heparin) in order to allow for anti-Xa factor levels of $0.1-0.3 \mathrm{U} / \mathrm{ml}$, and subsequently antiaggregants (aspirin, dipyridamole) once oral tolerance has been resumed. Antiaggregants are usually administered for at least 3 months, but treatment may be longer in case of risk factors. At the $9^{\text {th }}$ Consensus Meeting of the Spanish Society of Liver Transplantation, held in February 2021, an anticoagulation/antiaggregation treatment was established for pediatric liver transplantation. It is currently awaiting publication.

If re-transplantation is required in the immediate postoperative period, the so-called "code 0" (national priority) covers the first 30 days for pediatric patients $v s .7$ days in adults, given that adequate donors are more difficult to find. However, if arterial thrombosis occurs beyond the first 10 days, it will often be asymptomatic, because pediatric patients develop arterial collaterals quite rapidly since the hepaticojejunostomy carried out for biliary anastomosis has been performed, thus avoiding the need for an urgent LT - usually in children under 1 year of age. Some patients may require LT within a few years, though.

\section{PREFERENTIAL USE THERAPEUTIC MODALITIES}

Liver regeneration capacity, longer life expectancy following transplantation, and early onset of certain conditions make pediatric patients eligible for certain therapeutic options of limited use in the adult population.

\section{Auxiliary liver transplantation}

In exchange for saving their life, a liver transplant recipient becomes a chronic patient permanently exposed to rejection and re-transplantation risks, immunosuppressive treatment side effects, and de novo tumors. Therefore, the idea of "reversible" transplantation would be the perfect solution in fulminating hepatic failure (FHF). Auxiliary liver transplantation (ALT) involves implanting a full or reduced liver graft while leaving in place a part of the recipient's native liver, in order to make up for poor liver function (Fig. 7). If the native liver does not regenerate, the patient will have received a liver transplantation allowing for survival; and if it does, immunosuppressive treatment may be discontinued in order to allow for graft atrophy, which will free the patient from undergoing lifelong immunosuppressive treatment. The complexity of the procedure, the critical situation these patients are in, and the suboptimal results initially achieved have resulted in this technique being used in very few specialist centers globally ${ }^{(34.35)}$. Today, results are comparable with those from conventional transplantation, and nearly $75 \%$ of patients are discontinued from immunosuppressive treatment (IST). Therefore, ALT may become the technique of choice for FHF in the near future ${ }^{(36)}$. 


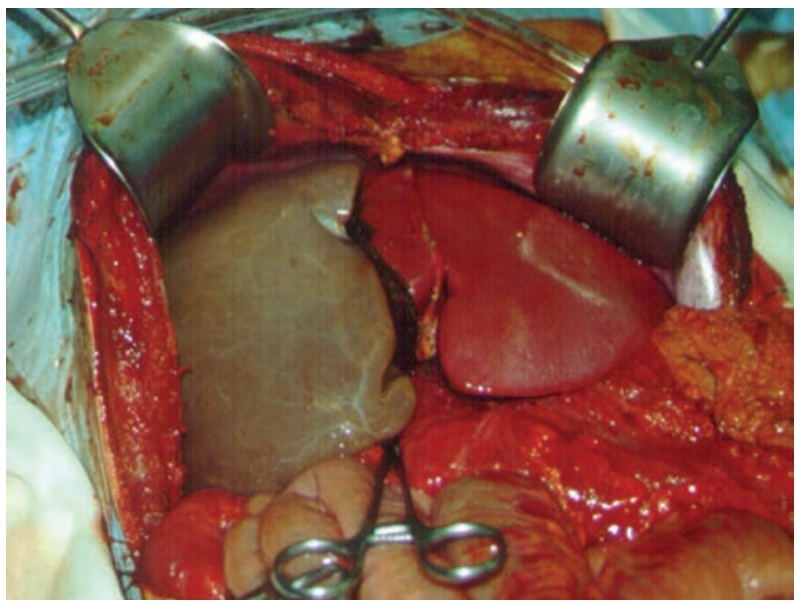

Figure 7. Auxiliary transplantation of the right hepatic lobe (picture from King's College Hospital).

Paracetamol overdose, hepatitis B and E, and mushroom intoxication are the FHF etiologies with the best regeneration prognosis. Decision as to whether this technique should be used or not depends on the quality of the donor's liver, the hemodynamic stability of the recipient, and the regeneration capacity of the native liver according to age and disease etiology. The histological appearance of the native organ can also determine regeneration possibilities - in case of total absence of viable hepatocytes, regeneration possibilities will be very low ${ }^{(34)}$.

In King's College Hospital, more than 160 ALTs have been performed, 80 of which in children. Half of these were carried out due to FHF, and the other half as a result of metabolic disease. LLS is the most frequent auxiliary liver graft in children weighting up to $30 \mathrm{~kg}$, whereas the right lobe, followed by the left lobe, are the most frequent auxiliary liver grafts in children weighting more than $30 \mathrm{~kg}$. In children weighting less than $10 \mathrm{~kg}$, ALT is not always feasible due to lack of space in the abdomen. In these cases, the main surgical challenge lies in performing hepatectomy in a patient with coagulopathy as a result of FHF. In this very hospital, a temporary partial portacaval shunt - between the branch of the right portal vein and the vena cava, in case of right hepatectomy - was carried out to diminish portal pressure and increase venous return in order to reduce bleeding and improve hemodynamic stability ${ }^{(37)}$. However, it should be noted that this technique may be more complex in younger children.

During postoperative management, the native organ will keep causing transaminase count to temporarily surge, which may be mistaken for graft rejection. Therefore, liver biopsy may be required in some cases. Once they have been discharged, patients undergo biopsy of the native graft 3-6 months following transplantation to corroborate viability, as well as an imaging test (CT-scan or MRI) and hepatobiliary scintigraphy to measure the volume of the native liver and the graft, the excretory function of both livers, and vascular permeability. These tests will be carried out every 6 months, while reducing immunosuppressive treatment to evaluate changes in function and size of the native organ.

ALT is also used in monogenic metabolic liver diseases with a structurally normal liver, such as type 1 Crigler-Najjar syndrome, urea cycle deficiency, propionic acidemia, hemophilia, or protein $\mathrm{C}$ deficiency ${ }^{(38.39)}$. In these cases, the objective is not to discontinue immunosuppressive treatment, but to replace the deficient enzyme while ensuring patient viability in case of complications with the transplanted liver. Long-term survival is similar to that found in patients with full liver replacement ${ }^{(40)}$. In Spain, Córdoba's group led the way in this field by performing an ALT from a living related donor in a patient with ornithine transcarbamylase deficiency ${ }^{(41)}$. In these cases, ALT surgery is more complex because the native liver is structurally normal, which means it does not offer any resistance to portal flow. This causes the portal blood to be "stolen," thus leading to graft atrophy and recurrence of the metabolic disease. To avoid this, portal flow should be adjusted during transplantation, which requires narrowing the portal vein of the native organ by means of a ligation in order to facilitate preferential flow to the liver graft. In spite of these actions, this complication has been described to occur a few years following transplantation, thus requiring re-transplantation or radiological adjustment of the portal flow through selective embolization of the portal branches.

More recently, various articles on the exchange of auxiliary livers between patients with different metabolic diseases - similar to domino transplantation - have been published. The objective is to optimize the use of liver grafts, for instance, between a patient with urea cycle deficiency and a patient with hemophilia A, or between a patient with Crigler-Najjar syndrome and a patient with urea cycle deficiency ${ }^{(42.43)}$.

\section{Liver cell transplantation}

Liver cell transplantation (LCT) or hepatocyte transplantation is a less invasive therapeutic alternative - both in metabolic liver disease without cirrhosis and in FHF which provides with a temporary solution until an organ is at hand, or until gene therapies allowing the disease to be treated are available. Hepatocyte infusion can be performed directly into the portal vein or the spleen after a catheter has been placed. It requires immunosuppressive treatment to avoid the rejection and destruction of these cells ${ }^{(44)}$. A more recent modality is the injection of hepatocytes encapsulated in alginate microspheres into the peritoneal cavity. This protects hepatocytes from being attacked by the recipient's immune system, which means no immunosuppressive treatment is required ${ }^{(45)}$.

The amount of cells to be infused is estimated between $5 \%$ and $10 \%$ of the weight of the liver. Liver grafts of 
cadaveric donors ruled out for transplantation, reduced grafts, and most recently, grafts from neonatal livers not eligible for transplantation as a result of high incidence of early arterial thrombosis are the main source of hepatocytes. Patients transplanted due to other metabolic diseases are also eligible for this, as if it were a domino $\mathrm{LCT}^{(46)}$.

LCT is safe. It does not heal the underlying condition, but it allows for a temporary improvement, which may be crucial until a definitive solution is found.

Despite their potential, these options are still not well established in Spain. In spite of its undeniable complexity, ALT has clear benefits in pediatric FHF, but implementation rates remain extremely low. Hepatocyte transplantation has been applied to a greater number of patients, but it is still limited today ${ }^{(47)}$.

\section{FUTURE CHALLENGES}

Patients under 2 years of age remain a challenge due to the risk of death while on the waiting list and to the surgical technique itself -, but in the last few years, the progressive improvement in LT results, with 20-year survival rates over $80 \%(48)$, has caused morbidity to be more common in the mid and long term as a result of immunosuppressive treatment (IST) side effects. Two thirds of late mortality in children are associated with immunosuppressant-related complications ${ }^{(49)}$. Tolerance to the graft by the recipient, defined as the possibility of discontinuing IST for a year or more with no impact on normal function (operational tolerance), has been studied for years. However, it has not been integrated into clinical practice yet because biomarkers allowing us to anticipate which patients could develop it have not been identified so far ${ }^{(50)}$. It should also be noted that an adequate liver function without IST does not rule out the presence of histological damage ${ }^{(51)}$. Improvements in survival rates and long-term quality of life will be determined by modifications in the current IST regimens, either due to the advent of the concept of tolerance, or to the development of customized ISTs.

\section{REFERENCES}

1. Starzl TE, Marchioro TL, Vonkaulla KN, Hermann G, Brittain RS, Waddell WR. Homotransplantation of the liver in humans. Surg Gynecol Obstet. 1963; 117: 659-76.

2. Bismuth H, Houssin D. Reduced-sized orthotopic liver graft in hepatic transplantation in children. Surgery. 1984; 95: 367-70.

3. Bucuvalas J. Long-term outcomes in pediatric liver transplantation. Liver Transpl. 2009; 15: S6-11.

4. Organización Nacional de Trasplantes. Actividad de Donación y Trasplante Hepático. España 2020. [Internet]. 2021. [Consultado el 10 Jun 2021]. Disponible en: http:// www.ont.es/infesp/Memorias/ACTIVIDAD\%20DE\%20
DONACIÓN\%20Y\%20TRASPLANTE\%20HEPÁTICO\%20 ESPAÑA.pdf

5. Kohli R, Cortes M, Heaton ND, Dhawan A. Liver transplantation in children: state of the art and future perspectives. Arch Dis Child. 2018; 103: 192-8.

6. Registro Español de Trasplante Hepático. Organización Nacional de Trasplantes. Memoria específica de resultados por UTH 2019. [Internet]. [Consultado el 24 Jun 2020]. Disponible en: https://sethepatico.org/downloadPriv.php?file=2019/MEMORIA _RETH2019_ESPECIFICA.pdf

7. Registro Español de Trasplante Hepático. Organización Nacional de Trasplantes. Memoria general de resultados 2019. [Internet]. [Consultado el 24 Jun 2020]. Disponible en: https://www. sethepatico.org/docs/2019/MEMORIA_RETH2019_GENE RAL.pdf

8. Hsu E, Perito ER, Mazariegos G. Save the children: the ethical argument for preferential priority to minors in deceased donor liver allocation. Clin Liver Dis. 2021; 17: 312-6.

9. Organización Nacional de Trasplantes. Datos globales de donación y trasplante. Memorias. http://www.ont.es/infesp/Paginas/ Memorias.aspx

10. Sociedad Española de Trasplante Hepático. Registro Español de Trasplante Hepático. Memoria General. https://www.sethepatico. org/reth-memoria-general.php

11. Organización Nacional de Trasplantes. Recomendaciones Nacionales sobre Donación Pediátrica. Mayo 2020. [Internet]. 2020. [Consultado el 8 Jun 2021]. Disponible en: http://www.ont.es/ infesp/DocumentosDeConsenso/Recomendaciones $\% 20$ Nacio nales\%20sobre\%20Donacion\%20Pediátrica.\%20Mayo\%20 2020.pdf

12. Thuong M, Ruiz A, Evrard P, Kuiper M, Boffa C, Akhtar MZ, et al. New classification of donation after circulatory death donors definitions and terminology. Transpl Int. 2016; 29: 749-59.

13. Weiss MJ, Hornby L, Witterman W, Shemie SD. Pediatric donation after circulatory determination of death: A scopping review. Pediatr Crit Care Med. 2016; 17: e87-e108.

14. Pérez Villares JM. Donación en asistolia. Cuad Med Forense. 2015; 21: 43-9.

15. Hessheimer AJ, Gastaca M, Miñambres E, Colmenero J, Fondevila C. Donation after circulatory death liver transplantation: Consensus statements from the Spanish Liver Transplantation Society. Transpl Int. 2020; 33: 902-16.

16. Perito ER, Roll G, Dodge JL, Rhee S, Roberts JP. Split liver transplantation and pediatric waitlist mortality in the United States: potential for improvement. Transplantation. 2019; 103: 552-7.

17. Organización Nacional de Trasplantes.Plan Nacional para el fomento de la bipartición hepática. Año 2020. [Internet]. 2020. [Consultado el 8 Jun 2021]. Disponible en: http://www.ont.es/ infesp/DocumentosDeConsenso/Plan\%20Nacional\%20para\%20 el\%20Fomento\%20de\%201a\%20Biparticion\%20Hepática.\%20 Año\%202020.pdf

18. Broering DC, Wilms C, Bok P, Fischer L, Mueller L, Hillert $\mathrm{C}$, et al. Evolution of donor morbidity in living related liver transplantation: a single-center analysis of 165 cases. Ann Surg. 2004; 240: 1013-24.

19. Hackl C, Schmidt KM, Süsal C, Döhler B, Zidek M, Schlitt H. Split liver transplantation: Current developments. World J Gastroenterol. 2018; 21: 5312-21. 
20. Su TC, Hung SW, Liu MC, Lin YT, Chen JH, Cheng SB, et al. Adult-to-adult living donor liver transplantation preoperative survey using MDCT, a single medical center experience in Taiwan. Kaohsiung J Med Sci. 2018; 34: 95-102.

21. Valentín-Gamazo C, Malagó M, Karliova M, Lutz JT, Frilling A, Nadalin S, et al. Experience after evaluation of 700 potential donors for living donor liver transplantation in a single center. Liver Transpl. 2004; 10: 1087-96.

22. Heaton N. Small-for-size liver syndrome after auxiliary and Split liver transplantation: Donor selection. Liver Transpl. 2003; 9: S26-S28.

23. Fukawaza K, Nishida S. Size mismatch in liver transplantation. J Hepatobiliary Pancreat Sci. 2016; 23: 457-66.

24. Bondoc AJ, Nathan JD, Alonso MH, Tiao GM. Solid organ transplantation in children. En: Holcomb III GW, Murphy JP, St Peter SD. Holcomb \& Ashcraft's Pediatric Surgery. China: Elsevier; 2020. p. 709-36.

25. Wan P, Li Q, Zhang J, Shen C, Luo Y, Chen Q, et al. Influence of graft size matching on outcomes of infantile living donor liver transplantation. Pediatr Transplant. 2015; 19: 880-7.

26. Yamamoto H, Khorsandi SE, Cortes-Cerisuelo M, Kawano Y, Dhawan A, McCall J, et al. Outcomes of liver transplantation in small infants. Liver Transpl. 2019; 25: 1561-70.

27. Ebel NH, Hsu EK, Dick AAS, Shaffer ML, CArlin K, Horslen SP. Decreased incidence of hepatic artery thrombosis in pediatric liver transplantation using technical variant grafts: Reports of the Society of Pediatric Liver Transplantation Experience. J Pediatr. 2020; 226: 195-201.

28. Flynn E, Huang JY, Hardikar W, Herd L, Hodgson A, Monagle P. Antithrombotic management and thrombosis rates in children post-liver transplantation: A case series and literature review. Pediatr Transpl. 2019; 23: e13420.

29. Sanada Y, Katano T, Hirata Y, Yamada N, Okada N, Ihara Y, et al. Interventional radiology treatment for vascular and biliary complications following pediatric living donor liver transplantation - a retrospective study. Transplant Int. 2018; 31: 1216-22.

30. Jurim O, Csete M, Gelabert HA, Millis JM, Olthoff K, Imagawa $\mathrm{D}$, et al. Reduced-size grafts-the solution for hepatic artery thrombosis after pediatric liver transplantation? J Pediatr Surg. 1995; 30: 53-5.

31. Mazariegos GV. Critical elements in pediatric allograft selection. Liver Transpl. 2017; 23: S56-S58.

32. Englesbe MJ, Kelly B, Goss J, Fecteau A, Mitchell J, Andrews W, et al. Reducing pediatric liver transplant complications: A potential roadmap for transplant quality improvement initiatives within North America. Am J Transplant. 2012; 12: 2301-6.

33. Nishida S, Kato T, Levi D, Naveen M, Berney T, Vianna R, et al. Effect of protocol doppler ultrasonography and urgent revascularization on early hepatic artery thrombosis after pediatric liver transplantation. Arch Surg. 2002; 137: 1279-83.

34. Quaglia A, Portmann B, Knisely A, Srinivasan P, Muiesan P, Wendon J, et al. Auxiliary Transplantation for Acute Liver Failure. Histopathological Study of Native Liver Regeneration. Liver Transpl. 2008; 14: 1437-48.

35. Kato T, Selvaggi G, Levi D, Hernández E, Takahashi H, Velasco M, et al. Routine use of auxiliary partial orthotopic liver transplantation for children with fulminant hepatic failure: preliminary report. Transplant Proc. 2006; 38: 3607-8.
36. Rela M, Kaliamoorthy I, Reddy MS. Current status of auxiliary partial orthotopic liver transplantation for acute liver failure. Liver Transpl. 2016; 22: 1265-74.

37. Cortés M, Vilca-Meléndez H, Heaton N. The use of temporary portocaval shunt as a technical aid in auxiliary orthotopic liver transplantation. Liver Transpl. 2016; 22: 1607-9.

38. Rela M, Muiesan P, Vilca-Meléndez H, Dhawan A, Baker A, Mieli-Vergani G, et al. Auxiliary partial orthotopic liver transplantation for Crigler-Najjar syndrome type I. Ann Surg. 1999; 229: 565-69.

39. Vara R, Turner C, Mundy H, Heaton N, Rela M, Mieli-Vergani $\mathrm{G}$, et al. Liver transplantation for propionic acidemia in children. Liver Transpl. 2011; 17: 661-7.

40. Sze Y, Dhawan A, Taylor R, Bansal S, Mieli-Vergani G, Rela M, et al. Pediatric liver transplantation for metabolic liver disease: experience at King's College Hospital. Transplantation. 2009; 87: 87-93.

41. Jiménez Gómez J. Desafíos del trasplante hepático infantil en los errores innatos del metabolismo. An Pediatr (Barc). 2018; 88: 61-2.

42. Read W. Reciprocal auxiliary partial liver transplant for inborn noncirrhotic metabolic diseases. Transplantation. 2007; 83: 1405-6.

43. Govil S, Shanmugam NP, Reddy MS, Narashiman G, Rela M. A metabolic chimera: two defective genotypes make a normal phenotype. Liver Transpl. 2015; 21: 1453-4.

44. Dhawan A, Mitry RR, Hughes RD, Lehec S, Terry C, Bansal $\mathrm{S}$, et al. Hepatocyte transplantation for inherited factor VII deficiency. Transplantation. 2004; 78: 1812-4.

45. Philippeos C, Dhawan A, Hughes RD, Fitzpatrick E, Lehec SC, Heaton N, et al. Effects of ascitic fluid on alginate-encapsulated human hepatocytes in vitro. Hepatology. 2010; 52 suppl: 1106A.

46. Pareja Ibars E, Cortés M, Tolosa L, Gómez-Lechón MJ, López $\mathrm{S}$, Castell JV, et al. Hepatocyte transplantation program: lessons learned and future strategies. World J Gastroenterol. 2016; 22: 874-86.

47. Pareja E, Cortés M, Gómez-Lechón MJ, Maupoey J, San Juan F, López R, et al. Estado actual y perspectivas futuras del trasplante de hepatocitos. Cir Esp. 2014; 92: 74-81.

48. Vimalesvaran S, Souza LN, Deheragoda M, Samyn M, Day J, Verma A, et al. Outcomes of adults who received liver transplant as young children. EClinicalMedicine. 2021; 38: 100987.

49. Ng VL, Alonso EM, Bucuvalas JC, Cohen G, Limbers CA, Varni JW, et al. for Studies of Pediatric Liver Transplantation (SPLIT) Research Group. Health status of children alive 10 years after pediatric liver transplantation performed in the US and Canada: report of the studies of pediatric liver transplantation experience. J Pediatr. 2012; 160: 820-6.

50. Feng S, Ekong UD, Lobritto SJ, Demetris AJ, Roberts JP, Rosenthal P, et al. Complete immunosuppression withdrawal and subsequent allograft function among pediatric recipients of parental living donor liver transplants. JAMA. 2012; 307 : 283-93.

51. Ekong UD, Melin-Aldana H, Seshadri R, Lokar J, Harris D, Whitington PF, Alonso EM. Graft histology characteristics in long-term survivors of pediatric liver transplantation. Liver Transpl. 2008; 14: 1582-7. 